\title{
Introducing Training on Doctor-Patient Communication Skill among the Pre-Intern Physicians: A Suggested Model
}

\author{
Dr. Mehrunnissa Khanom ${ }^{1}$, Dr. Maliha Ata ${ }^{2}$, Dr. Rummana Khair ${ }^{3}$, Dr. Aniruddha Ghose ${ }^{4}$, Professor M A Faiz ${ }^{5}$
}

\begin{abstract}
Proper doctor-patient communication produces therapeutic benefit on the patient. The arts and tips of communication skill can change the feelings of a patient forever. Good communication skill should have verbal, non-verbal and para-verbal components. Unfortunately, many postgraduate doctors of our country cannot satisfy the demand of their patients due to lack of training on communication skills. In this paper, a model for communication skill training has been proposed for newly graduated doctors which includes formal lecture, video demonstration, role play and evaluation by creating different scenarios. The selected time for communication skill training would be the time gap between publication of result of final professional MBBS and starting the internship training. With increasing demand of creating more communicative physicians, implementation and further recommendations on communication skill training for new graduates are encouraged.
\end{abstract}

Key words: Communication skill; doctor-patient relationship; internship; empathic approach.

\section{Introduction}

Patient-physician communication is an integral part of clinical practice. When done well, such communication produces a therapeutic effect for the patient ${ }^{1-4}$. Unfortunately, the communication skills of busy physician often remain poorly developed due to isolated academic settings in early postgraduate years. Serious miscommunication is a potential pitfall, especially in terms of patents' understanding, expectation and involvement in treatment ${ }^{5-8}$. Today, patients recognize that they are not passive recipients, but are members of expert authority that takes part in decision making ${ }^{9}$. Though doctor-patient communication is an integral component of high quality health-care, there are always lots of dissatisfactions about the attitude of physicians towards patients and this scenario is very common in our country. A large number of our patients are going abroad every year for treatment of medical conditions

\footnotetext{
1. Dr. Mehrunnissa Khanom

Assistant professor, Department of Medicine

Chattagram International Medical College, Chittagong.

2. Dr. Maliha Ata

Associate professor, Department of Pharmacology \& Therapeutics, Chattagram Maa-O-Shishu Hospital Medical College, Chittagong.

3. Dr. Rummana Khair

Assistant professor, Department of Anatomy

Southern Medical College and Hospital, Chittagong.

4. Dr. Aniruddha Ghose

Associate Professor, Department of Medicine

Chittagong Medical College

5. Prof. M A Faiz

Professor, Department of Medicine

Former DG, Directorate General of Health Services.
}

Address of correspondence: Dr. Mehrunnissa Khanom

Assistant professor, Department of Medicine

Chattagram International Medical College

Email:drmehrun.k@gmail.com that can be nicely handled by our physicians, this scenario not only causes loss of huge foreign currency, but also loss of image of our nation ${ }^{10}$. The current paper summarizes the components of good communication skill, the barriers, the importance of communication skill training for intern doctors as well introduces an assessment scale for evaluation of intern doctors' communication skills.

\section{Materials and methods}

In this review, Google scholar has been used as search engine. The papers were searched using key terms 'doctorpatient relationship', 'communication skills' 'internship training' 'arts of communication' and selected reviewing the abstracts for their relevance to this specific study. How many were actually extracted \& studied? How many relevant were being used ultimately?

\section{Communication skill: what and when:}

Communication is the way how a physician interacts with the patient; it lies at the heart of good medical practice. A doctor's communication and interpersonal skills encompass the ability to gather information in order to facilitate accurate diagnosis, counsel appropriately, give therapeutic instructions, and establish caring relationships with patients. A physician practices communication skill thousands and millions throughout his lifetime ${ }^{11-14}$. The arts and tips of communication skill can change the feelings of a patient forever. The most important fields of practicing communication skill are critical care, palliative care, oncology, surgery. Timely and organized communication session with patients and relatives, relieves the anxiety, improve confidence, allows mental preparation, reduces hospital burden and minimizes unfavorable incidences ${ }^{15,16}$.

\section{Components of good communication skill:}

According to the psychologist Albrt Mehrabian, among the total meaning of a spoken message, $55 \%$ comes from facial

Bangladesh Journal of Medical Education 2018;9(2):32-36. (C) 2018 Khanom et al., publisher and licensee Association for Medical Education. This is an Open Access article which permits unrestricted non-commercial use, provided the original work is properly cited. 
expressions and other non-verbal communication, 38\% comes from tone and language and $7 \%$ comes from actual meaning of the words. Good communication skill should have verbal, non-verbal and paraverbal components ${ }^{17}$.

\section{Verbal:}

The art of talking, communicating and giving information, which includes course and prognosis of disease, various treatment option available, nature, cost, yield of investigation and risk/ benefit of invasive procedure available.

\section{Non-verbal:}

Attentive gesture, correct posture, eye contact, active listening, encouraging the patient to talk, etc.

\section{Para-verbal:}

Tone, pitch, volume, pacing of voice ${ }^{18}$.

The Accreditation council for graduate medical education recommends that a physician should become competent in five key communication skills: listening effectively, eliciting information, providing information, counseling patients and making informed decisions ${ }^{19}$. Some practical steps to improve patient-physician rapport include:

\section{Ensuring a comfortable environment for discussion:}

During discussion, the patient and physician must have comfortable environment and surroundings with appropriate privacy, if applicable. A noisy, messy, poorly eliminated room makes physically unacceptable circumstances. The physician's appropriate body language at a tidy, quiet room increases confidence of audiences.

\section{Assessing prior understanding:}

It is important to know what the patient or attendant already knows, that will help the physician to determine the point from which discussion may start ${ }^{6,20}$.

\section{Assessing expectations of patient:}

With proper communication skill, physician should assess any desire or concerns of patient in a clear and understandable manner. It will guide the doctor to focus on those special issues.

\section{Being empathic:}

Empathy is the basic skill with which a physician recognizes and acknowledges expressed or unexpressed emotions of a patient, considering himself in the position of patient ${ }^{21-23}$.

\section{Telling the truth:}

Telling the truth is a divine quality. Physician must provide true information clearly and understandable in a step-wise fashion. Euphemism may soften the delivery of sad news; however, can be extremely misleading and confusing.

\section{Being hopeful:}

In situations where medical therapy fails, hope can be conveyed to the family by reassurance and offering palliative therapy. At the point of imminent death of a patient, family should be discussed about ways to provide maximum comfort and minimal sufferings of dying patient ${ }^{24}$.
Silence, when appropriate:

It is said that "silence is golden", when appropriate ${ }^{25}$. Proper body language with appropriate pause allows time to the listener to absorb new information and formulate any question. During breaking a bad news, silence gives enough scope to the recipient to express his or her emotions and reactions.

\section{Being prepared for any reaction:}

As a human being, any patient has inherent tendency to react in response to an unacceptable fact. That tendency varies from person to person, and a physician must be prepared ahead to response sincerely when reaction comes from patient ${ }^{26-28}$.

\section{The barriers \& problems of communication skill:}

Several barriers have been identified between doctor-patient relationships. Barriers on part of physician include authoritarian or dismissive attitude, hurried approach, work overload, use of jargon, language barrier and poor experience on patient's cultural background. Barriers on behalf of patient include physical or mental impediment, anxiety, fear, misconceptions and conflicting sources of information ${ }^{29-30}$.

\section{Importance of communication skill training for intern doctors:}

Communication is the heart and art of medicine and a central component in the delivery of health care. The main goals of current doctor-patient communication are creating a good interpersonal relationship, facilitating exchange of information, and including patients in decision making. Effective doctor-patient communication can be a source of motivation, re-assurance, support and positive view of patient about their health. However, being human being, doctors have different innate talents which are subjected to be modified and refined if properly guided. The internship is a transition from a medical student to a certified doctor, when a new graduate takes formal training on basic skills of patient management. Many countries offer formal training and workshops on communication for freshly graduated doctors before they start internship ${ }^{31-35}$.

Until recently, the content, structure and function of communication skill has received very little attention in undergraduate studies in Bangladesh. As a result, the new graduates, while at internship training, have to handle difficult clinical scenario at new environment without prior orientation. Even if supervised, mishandling of those situations sometimes create miscommunication, patient dissatisfaction and loss of confidence on behalf of doctors. In addition, medical profession requires a high level of interpersonal communication with colleagues, co-workers and seniors in a clear manner by means of verbal or written cues. This requires an understanding on common terms and manners of paper-works as well as documentation.

\section{Introducing communication skill training for intern doctors:}

The authors propose introducing and including formal training for communication skills for graduated doctors in 
our country in order to improve patient outcome as well as reduce unpleasant circumstances.

The selected time for communication skill training would be the time gap between publication of result of final professional MBBS and starting the internship training. Before starting internship, all interns must acquire the communication skill training certificate, endorsed by the supervisors. The proposed model is as follows:

\begin{tabular}{|l|l|}
\hline \multicolumn{2}{|c|}{ Day 0: Introduction + Pre-test } \\
\hline 8.00am - 9.00am & $\begin{array}{l}\text { Registration, colour coding, distribution } \\
\text { of program schedule }\end{array}$ \\
\hline 9.00am - 10.30am & Introduction \& inaugural session \\
\hline $10.30 \mathrm{am}-11.00 \mathrm{am}$ & Tea break \\
\hline $11.00 \mathrm{am}-1.30 \mathrm{pm}$ & Pre-test \\
\hline $1.30 \mathrm{pm}-1.45 \mathrm{pm}$ & Lunch \\
\hline $1.45 \mathrm{pm}-2.00 \mathrm{pm}$ & Investigator's meeting \\
\hline
\end{tabular}

\begin{tabular}{|l|l|}
\hline \multicolumn{2}{|l|}{ Day 1: Training } \\
\hline 8.30am - 8.45am & $\begin{array}{l}\text { Lecture 1: Introduction to communication } \\
\text { skill }\end{array}$ \\
\hline 8.45am - 8.55am & Video 1: Taking consent for a procedure \\
\hline 8.55am - 9.10 am & $\begin{array}{l}\text { Lecture 2: Components of communication } \\
\text { skill }\end{array}$ \\
\hline 9.10am - 9.20am & Video 2: Information giving \\
\hline 9.20am - 9.35am & $\begin{array}{l}\text { Lecture 3: Barriers of doctor-patient } \\
\text { Communication }\end{array}$ \\
\hline 9.35am - 9.45am & Video 3: Practising autonomy \\
\hline 9.45am - 9.55am & Video 4: Telling the truth \\
\hline 10.00am - 10.30am & Tea break \\
\hline 10.30am -12.30 pm & $\begin{array}{l}\text { Small group teaching (role play + group } \\
\text { discussion) }\end{array}$ \\
\hline 12.30pm - 1.00pm & Review \& reflection \\
\hline 1.00pm - 1.20pm & Lunch \\
\hline
\end{tabular}

\begin{tabular}{|l|l|}
\hline \multicolumn{2}{|c|}{ Day 2: Training } \\
\hline 8.45am - 8.55am & Video 5: Breaking bad news \\
\hline 8.55am - 9.05am & $\begin{array}{l}\text { Video 6: Maintaining confidentiality of } \\
\text { patient }\end{array}$ \\
\hline 9.05am - 9.15am & Video 7: Communication with colleague \\
\hline 9.15am - 9.25am & Video 8 Reaction to annoyed attendant \\
\hline 9.25am - 9.35am & $\begin{array}{l}\text { Video 9: Handling with fault of self/ } \\
\text { colleague }\end{array}$ \\
\hline 9.35am - 9.35am & Video 10: Doing justice to patient \\
\hline 9.45am - 10.00am & Review \\
\hline 10.00am - 10.30am & Tea break \\
\hline 10.30am- 12.30am & $\begin{array}{l}\text { Small group teaching (role play + group } \\
\text { discussion) }\end{array}$ \\
\hline 12.30am - 1.00pm & Review \\
\hline 1.00pm - 1.30pm & Lunch \\
\hline
\end{tabular}

\begin{tabular}{|l|l|}
\hline \multicolumn{2}{|c|}{ Day 3: Post-test + Closing Session } \\
\hline 9.00am - 12.00pm & Post-test (experimental \& control group) \\
\hline $12.00 \mathrm{pm}-12.30 \mathrm{pm}$ & Closing program \\
\hline $12.40 \mathrm{pm}-1.00 \mathrm{pm}$ & Lunch \\
\hline
\end{tabular}

The trainers of the model would be consultants and teachers from clinical subjects, selected by heads of clinical departments. Surrogates and volunteers can be encouraged from existing interns and medical officers.

\section{Conclusion}

There is a need for inclusion of communication skill training after the end of graduation and before starting internship. This window period is vital, because this is the time when young doctors are mentally relaxed and ready to learn new techniques necessary for the upcoming internship. A model for communication skill training has been proposed which includes formal lecture, video demonstration, role play and evaluation by creating different scenarios. This model can be applied to a small group of newly graduated physicians and the difference in outcome can be assessed. If appropriate, it can further be implemented and included in the curriculum with the aim of producing more communicative physicians.

\section{Conflicts of interest}

The authors have no conflict of interest.

\section{Acknowledgement}

The authors sincerely thank Prof. Pradip Kumar Dutta, Head, Department of Nephrology and Vice Principal, Chittagong Medical College, for his scholarly review of this article.

\section{References}

1. Communication skills education for doctors: an update. Board of Medical education. British Medical Association; London 2004. p 3-15.

2. Usherwood T. In: Understanding the Consultation: Evidence, Theory and Practice. Buckingham: Open university Press, 1999. chapter 2: Information sharing in the consultation.

Bangladesh Journal of Medical Education 2018;9(2):32-36. 
3. DiMatteo MR. The role of the physician in the emerging health care environment. West J Med. 1998; 168(5):328-33.

4. Miller SM, Brody DS, Summerton J. Styles of coping with threat: implications for health. J Pers Soc Psychol. 1988; 54(1):142-8.

5. Huntington B, Kuhn N. Communication gaffes: a root cause of malpractice claims. Proc (BaylUniv Med Cent). 2003; 16:157-61.

6. Bre'dart A, Bouleuc C, Dolbeault S. Doctor-patient communication and satisfaction with care in oncology. Curr Opin Oncol. 2005;17(14):351-4.

7. Arora N. Interacting with cancer patients: the significance of physicians' communication behavior. Soc Sci Med. 2003; 57(5):791-806.

8. Lee SJ, Back AL, Block SD, Stewart SK. Enhancing physician-patient communication. Hematology Am Soc Hematol Educ Program. 2002; 1:464-83.

9. Travaline JM, Ruchinskas R, D'Alonzo GE. PatientPhysician Communication: Why and How. JAOA.2005; 105 (1):13-8.

10. MS Islam, ST Jhora. Physician-Patient relationship: The present situation and our responsibilities. Bangladesh medical journa.12012; 41(1):55-58

11. Duffy FD, Gordon GH, Whelan G et al. Assessing competence in communication and interpersonal skills: the Kalamazoo II report. Acad Med. 2004; 79(6):495507.

12. Van Zanten M , Boulet JR, McKinley DW, Dechamplain, Jobe AC. Assessing the communication and interpersonal skills of graduates of international medical schools as part of the United States Medical Licensing Exam (USMLE) Step 2 Clinical Skills (CS) Exam. Acad Med. 2007; 82(10 Suppl):65-8.

13. Brédart A, Bouleuc C, Dolbeault S. Doctor-patient communication and satisfaction with care in oncology. Curr Opin Oncol. 2005; 17(14):351-4.

14. Platt FW, Keating KN. Differences in physician and patient perceptions of uncomplicated UTI symptom severity: understanding the communication gap. Int $\mathrm{J}$ ClinPrac. 2007; 61(2):303-8.

15. Kelly L. Listening to patients: a lifetime perspective from. Ian McWhinney. Canadian Journal of Rural Medicine.1998; 3:168-9.

16. Gokul J Jorwekar, Dilip K Apturkar, Padmakar K Baviskar, Meena H Shaikh. Training of Intern Doctors with interpersonal communication (IPC): A step toward better doctor-patient relationship. International Journal of Biomedical and Advance Research. 2015; 6(05); 422-426.

17. Robertson K. Active listening: more than just paying attention. Aust Fam Physician. 2005; 34:1053-5.

18. Accreditation Council for Graduate Medical Education. Toolbox for the evaluation of competence. version 1.1 Sept 2000.

19. Lester GW, Smith SG. Listening and talking to patients. A remedy for malpractice suits? West J Med. 1993; 158:268-72.

20. Singer HK, Ruchinskas RA, Riley KC, Broshek DK, Barth JT. The psychological impact of end-stage lung disease. Chest. 2001; 120(4):1246-52.

21. Buckman R. Basic how to break bad news: a guide for health-care professionals. In: communication skills. London: Papermac; 1992: 32-53.

22. Brittin ME. Keys to improving your listening skills. Fam Pract Manag. 2005; 12:68-772.

23. Ramirez AJ, Graham J, Richards MA, Cull A, Gregory WM. Mental health of hospital consultants: the effects of stress and satisfaction of work. Lancet. 1995; 16:724-8.

24. Kaplan SH, Greenfield S, Ware JE Jr. Assessing the effects of physician-patient interactions on the outcomes of chronic disease. Med Care. 1989; 27(3 Suppl):110-27.

25. Levinson W, Roter DL, Mulooly JP, Dull VT, Frankel RM. Doctor patient communication. The relationship with malpractice claims among primary care doctors and surgeons. JAMA. 1997; 277:553-9.

26. Roter DL. Physician/patient communication: transmission of information and patient effects. $\mathrm{Md}$ State Med J. 1983; 32(4):260-65.

27. Stewart MA. Effective physician-patient communication and health outcomes: a review. CMAJ. 1995; 152(9):1423-33.

28. Khan TM, Hassali MA, A-Haddad MSM. Patientphysician Communication Barrier: A Pilot Study Evaluating Patient Experiences. Journal of young pharmacist. 2011;3(3);250-55.

29. Walker BR, Colledge NR, Ralston SH, Penman ID. Davidson's principles \& practice of medicine. $22^{\text {nd }} \mathrm{ed}$. Churchill Livingstone Elsevier, London: 2014. p 2-5.

30. Brown JB, Boles M, Mullooly JP, Levinson W. Effect of clinician communication skills training on patient satisfaction: a randomized, controlled trial. Ann Intern Med. 1999; 131(11):822-9.

31. Dangol B. Internship: A closer look at its prospects. Kathmandu University Medical Journal. 2008; 6(21): 141-3.

32. Cegala DJ, Marinelli T, Post D. The effects of patient communication skills training on compliance. Archives of Family Medicine. 2000; 9: 57-64.

Bangladesh Journal of Medical Education 2018;9(2):32-36. 
33. Shukla AK, Yadav VS, Kastury N. Doctor-Patient Communication: An important but often ignored aspect in Clinical Medicine. JIACM. 2010; 11(3):208-11.

34. Stewart M, Brown JB, Donner A et al. The impact of patient entered care on outcomes. J. FamPract. 2000; 49(9):796-804.
35. Maguire P, Fairbairn S, Fletcher C. Consultation skills of young doctors: Benefits of feedback training in interviewing as students persist. BMJ. 1986; 292:1573-6. 